$$
\text { "tmcs-barczi-report" — 2010/4/12 — 23:54 — page } 169 \text { — \#1 }
$$

\title{
Report on the "English Language Section of Varga Tamás Days 2009"
}

\author{
Compiled by Krisztina BARCZI
}

Abstract. The 9th English Language Section as a part of the Varga Tamás Days was organised by the Department of Mathematics Education at the Teacher Training Institute of the Eötvös Loránd University. We report on the talks and the following discussions in this section.

Key words and phrases: teaching geometry, young researchers, motivating students, mathematical skills, international professional relationship.

ZDM Subject Classification: A60.

On the 7th and 8th of November the Department of Mathematics Education at the Teacher Training Institute of the Eötvös Loránd University organised the Varga Tamás Days which is an annual conference for those who are interested in teaching and learning Mathematics.

The English language section is organised by Katalin Munkácsy. Details about the conference and this section can be found at: http://mathdid.elte. $\mathrm{hu} / \mathrm{html} / \mathrm{vtn} 2009$. html. This section has been giving an opportunity for years for teachers, students and researchers both from Hungary and from other countries to share their ideas, concerns and to discuss their questions related to Mathematics education. As part of the English language section a number of very interesting and thought-provoking talks were presented which were usually followed by heated discussions. One question or comment lead to another very exciting remark. Sharing your ideas and listening to the others' comments help you to look at

Copyright (C) 2010 by University of Debrecen 


$$
\text { "tmcs-barczi-report" — 2010/4/12 — 23:54 — page } 170 \text { — \#2 }
$$

your own issues or statements from a different point of view and are essential in developing your research. Unfortunately, some of these discussions had to be left unfinished because of the time limit, but we had the chance to exchange further ideas and views about the different issues after the section.

As a participant and a teacher who is passionate about teaching Maths I see this event as an excellent forum that helps you to keep your enthusiasm about what you do and makes you see that there are colleagues who equally care about improving Maths eduction and are trying to make a difference.

The talks suggested that despite the fact that in the different countries the national curricula are different and the cultural backgrounds are quite diverse, it seems that in teaching Maths all teachers have to face similar problems in their everyday work. These issues usually are: motivating students whose future plans have hardly anything to do with Mathematics, help and deepen students' understanding in various mathematical areas, bring Maths education closer to their everyday experiences... etc.

This section had two main threads: one geometrical and one dealing with everyday problems of Maths teachers. The geometrical talks had quite a wide range as well, from bouncing balls through the geometrical thinking of students to the fascinating field of topology. The other thread was by no means less interesting as we could learn about Zimmerman's "hard" and "soft" elements representing mathematical skills, how to make boring Maths tasks more appealing for not so motivated students, concerns in the field statistics in Croatian Maths education ... etc. For a more detailed look here are the abstracts of the talks. ${ }^{1}$ The chairman of the section was Zsolt Lavicza who demonstared the use of an excellent software package, the GeoGebra. The invited speaker of the session, Paul Andrews showed us an interesting graphical proofs of Euclid's number theorem.

\section{Abstracts of talks \\ Graphical proof of Euclid's perfect number theorem Paul Andrews University of Cambridge}

In this session I intend to share with colleagues a delightful graphical proof of Euclid's perfect number theorem. I do not claim the result as my own but draw on the work of Roger Nelson in the US and Bob Burn in England. However, I

${ }^{1}$ Please note that some of the abstracts had to be edited due to space limitations. 


$$
\text { "tmcs-barczi-report" — 2010/4/12 — 23:54 — page } 171 \text { — \#3 }
$$

believe it shows, in an elegant and entirely convincing manner, that if $p=2^{n+1}-1$ is prime, then $N=2^{n} p$ is perfect.

\author{
Geometric sequences and the Hungarian Dance Academy \\ Péter Fejes Tóth \\ University of Debrecen \\ Hungarian Dance Academy, Budapest, Hungary \\ E-mail: fejestothpeter@yahoo.com
}

I teach matemathics at the high school of the Hungarian Dance Academy. It may sound not that exciting, but believe me, it is full of challenges, as most of my students know exactly what to do in their lives, and it has - or at least they think it has - nothing to do with matemathics. They work very hard to become good dancers, but they hardly make any effort to learn matemathics at all. It is my job to make them realize, that matematics is not just a beautiful science and the best way to learn thinking, but in many aspects it can be a very useful tool even in their everyday life. In my presentation I will show some problems connected to geometric sequences which were proved to be very useful in awakening my students' interest.

\title{
Some questions of topology: Geometric calculation of the 4th stable homotopy group of spheres$$
\text { Csaba Nagy }
$$ \\ Eötvös Loránd University \\ E-mail: csaba224@freemail.hu
}

I'm currently doing a research in the field of differential topology. In my paper I give a new proof of the fact that $\pi_{n+4}\left(S^{n}\right)=0$ for $n$ large enough, i.e. every continuous map $S^{n+4} \rightarrow S^{n}$ is homotopic to the constant map. The proof is based on the Pontryagin construction, which defines a correspondence between the homotopy classes of smooth maps $V^{n+k} \rightarrow S^{n}$ and the framed cobordism classes of $k$-dimensional framed submanifolds of $V^{n+k}$. I show that every submanifold $M^{4}$ in $S^{n+4}$ is framed cobordant to the sphere $S^{4}$ and so is framed cobordant to 0 . I will talk about the basic notions of differential topology, and present the Pontryagin construction. Then I briefly show how it can be applied to solve this problem of algebraic topology. 


$$
\text { "tmcs-barczi-report" — 2010/4/12 — 23:54 — page } 172 \text { — \#4 }
$$

The Requirements in Statistics Education - Comparison of PISA Mathematical Tasks and Tasks from the Mathematical Textbooks in the Field of Statistics

Dubravka Glasnovic Gracin and Predgrag Vukovic

University of Zagreb, Croatia

E-mail: duda@hazu.hr,predrag.vukovic@vus-ck.hr

This work presents the results of the didactical analysis of mathematical textbooks in the field of statistics. The analysis is based on the three most represented mathematical textbooks for obligatory education in 7th grade in Croatia. The intention of the research is to determine mathematical requirements in obligatory statistics education in Croatia, as well as to establish the extent to which these requirements match the requirements of PISA assessment. The analysis shows that PISA's released statistics problems have in many ways different mathematical requirements from the requirements of textbook problems in the statistics chapters. The results also show that while PISA puts strong emphasis on the statistics field, in the current Croatian curriculum this field is barely present. These discrepancies in requirements and portion of statistics activities surely affect the results of Croatian pupils on PISA assessment in the field of mathematical literacy.

Teaching Maths in English for Hungarian students

$$
\text { Krisztina Barczi }
$$

University of Debrecen

Neumann János Secondary School, Eger

E-mail: bkrixta@gmail.com

Why do we teach Maths in English in Hungary? Why do students want to learn Maths in a foreign language? There are several answers for these questions, and different purposes imply different requirements that may or may not be fulfilled. This talk surveys these possible choices with special emphasis on the problems that teachers may have in their day-to-day work (including discrepancies between national curricula, language problems, difference in the approach of teaching certain topics... etc ). The talk is based on a 3 year teaching experience in England (in 2 different secondary schools) compared to the current state of affair in Hungary. 


$$
\text { "tmcs-barczi-report" — 2010/4/12 — 23:54 — page } 173 \text { — \#5 }
$$

Report on the "English Language Section of Varga Tamás Days 2009"

Knowledge Management Implications for Mathematics Education

Jozef Hvorecky

Vysoká škola manažmentu, Bratislava, Slovakia

University of Liverpool, Liverpool, United Kingdom

E-mail: hvorecky@chello.sk

Mathematics belongs to the least popular school subjects. A lot of time has been spent on searching methods that could change this unfortunate situation. The author, a lecturer at a School of Management, discusses the issue as a managerial problem. Using Knowledge Management concepts, we will demonstrate an imbalance between tacit and explicit knowledge caused by methodologies favoring the latter ones. Examples of the approaches that might increase learners' tacit knowledge are our second goal. We will commence this part of the lecture by showing that not all elements of Zimmerman's octagon are covered equally by current mathematics courses. The "hard" ones (Find, Construct, Evaluate, and Calculate) are dominating; the "soft" ones (Order, Play, Apply, and Argue) appear in the curriculum exceptionally. As all eight elements represent basic mathematical skills, they should be present in a more balanced manner. In our presentation, we will demonstrate potential benefits of the "soft skills" and concentrate on issues like: Why should we make Mathematics Education more attractive? How to do it without weakening its quality? How to explain its strengths and weaknesses in a popular language and why? Can information technology help us and, if so, how?

The formation of geometrical terms Katalin Földesi

Mälardalens Högskola Eskilstuna-Västerås, Sweden

University of Debrecen, Hungary

E-mail: katalin.foldesi@mdh.se

Coming from a geometry-rich teaching environment, I ended up in an environment lacking geometry teaching. For a long time, the difference between the two environments was shocking. But how to go about mapping this unbelievable difference using the tools of mathematical didactics? I found help in the didactic theory of two Dutch researches, Pierre and Dina van Hiele. This theory formulates the levels and some regularities of the geometric thinking of students. The wide-spread adaptation of this model was a great help in rebuilding geometry teaching on new foundations as well as the successful development of it. A few 


$$
\text { "tmcs-barczi-report" — 2010/4/12 — 23:54 — page } 174 \text { — \#6 }
$$

decades later an American research group, lead by Professor Usishkin in Chicago, developed and tried out a test to map the Van Hiele levels of students. After presenting some of the results of this group's meticulous research, I would like to present my own research results. I had several groups of college students to take the test. With the help of my supervisor, during the fall of 2009 I had a group of Hungarian teacher students who took the test as well. The analysis of the results naturally lead to the question: how could the test results be used in the development of the subject-matter of instruction of a short geometry course? At the time of this presentation lectures related to such a geometry course are already underway, and I would like to present some parts of it.

\section{GeoGebra Institutes, Research, and Development Zsolt Lavicza \\ Faculty of Education, University of Cambridge}

GeoGebra is rapidly gaining popularity in the teaching and learning of mathematics around the world. Currently, GeoGebra is translated to 50 languages, used in 190 countries, and downloaded by approximately 300,000 users in each month. This increased use compelled the establishment of the International GeoGebra Insitute (IGI) that serves as a virtual organization to support local GeoGebra initiatives and institutes. This structure enables the GeoGebra community to suit the software use for local needs and enthusiast to contribute to the community according to their interests. The aims of local GeoGebra Institutes (GI) are to offer teacher training, develop teaching materials, carry out research, and outreach to disadvantaged communities. In my talk, I will review examples of the work of some GIs and outline some research projects that assist the GeoGebra community to employ the software even more successfully. In addition, I will talk about the future of software and material development.

\section{Interactive mathematical games for young students Ignác Bontovics \\ Szent István University \\ E-mail: bignacz@gmail.com}

Nowadays many educational games are available both for teachers and students. We also had some ideas which were accomplished. We chose topics that 
fit into the Hungarian curriculum and are a bit more difficult to teach than the average. Programs to be illustrated during presentation are simple; they can be used online on the internet or without the internet, in offline mode. You can see them on my homepage. According to our experience these mathematical games reach desired development goals with 8-10 years old children. I would like to show some example of maths games (developed by us). These short pieces of software help young students to understand some elements of spatial orientation, logic and probability.

UNIVERSITY OF DEBRECEN

NEUMANN J. SECONDARY SCHOOL

EGER

HUNGARY

E-mail: bkrixta@gmail.com

(Received January, 2010) 